\title{
4D Printing of Lead Zirconate Titanate Piezoelectric Composites Transducer Based on Direct Ink Writing
}

Kai Liu $u^{1,2}$, Qingqing Zhang ${ }^{2}$, Chenyang Zhou ${ }^{2}$, Yusheng Shi ${ }^{3}$, Ce Sun ${ }^{4}$, Huajun Sun ${ }^{1,2,4 *}$,
Changxia Yin ${ }^{4}$, Jiaming $\mathrm{Hu}^{2}$, Shuyu Zhou ${ }^{2}$, Yuzhen Zhang ${ }^{2}$ and $\mathrm{Yu} \mathrm{Fu}^{2}$

${ }^{1}$ State Key Laboratory of Silicate Materials for Architectures, Wuhan University of Technology, Wuhan, China, ${ }^{2}$ School of Materials Science and Engineering, Wuhan University of Technology, Wuhan, China, ${ }^{3}$ State Key Laboratory of Materials Processing and Die and Mould Technology, Huazhong University of Science and Technology, Wuhan, China, ${ }^{4}$ Advanced Ceramics Institute of Zibo New and High-Tech Industrial Development Zone, Zibo, China

Lead zirconate titanate (PZT) piezoelectric composites used in transducers were fabricated via direct ink writing (DIW) combined with furnace sintering and resin impregnation. A ceramic slurry with a volume fraction of $52 \mathrm{vol} \%$ and suitable viscoelasticity was prepared. After post-process, the PZT ceramic specimens showed a nanoscale grain size with a density of $7.63 \mathrm{~g} / \mathrm{cm}^{3}$, accounting for $97.8 \%$ of the theoretical density. The effects of different printing rod spacing on the electrical properties of composites were evaluated and lucubrated. Finally, an underwater acoustic transducer was assembled by using the PZT piezoelectric composites fabricated by the above method. The electrical signal generated by the underwater acoustic transducer changed autonomously with the acoustic stimulation, which indicated the application mode of $4 \mathrm{D}$ printing in functional devices in the future.

Keywords: 4D printing, DIW, piezoelectric composites, performance, underwater acoustic transducer

\section{INTRODUCTION}

Underwater acoustic transducer is a kind of functional device that can convert acoustic and electrical signals into each other and its core component is piezoelectric composite material (Tian et al., 2021; Li et al., 2006; Rouffaud et al., 2015). Compared with 0-3, 1-3 and, 2-3 piezoelectric composites, 3-3 ceramic/polymer composites have a bi-continuous architecture comprising an active ferroelectric ceramic phase and a passive flexible polymer phase, which possess high hydrostatic pressure sensitivity and good coupling properties with water, thereby improving the bandwidth and transmitting and receiving sensitivity of the transducer (Newnham et al., 1978; Tressler et al., 1999; Bowen and Topolov, 2003). But traditional fabricating methods, such as the self-assembly method (Liu et al., 1996), the gel-casting method, the cutting-filling method (Viganò et al., 2017) and so on, have certain disadvantages like low material utilization, long production cycles and limited product complexity (Woodward et al., 2015).

Additive manufacturing (AM) technology has the advantage of being easy to prepare complex structural parts, including direct ink writing (DIW), digital light processing (DLP), selective laser sintering (SLS) and other methods. The principle of DIW is to extrude viscoelastic ink from the needle head to form rod-shaped fibers. As the needle head moves, the rod-shaped fibers are deposited into a specific pattern (Revelo and Colorado, 2018; Coppola et al., 2021). DLP technology is to project patterned ultraviolet light onto the photocurable material to cure each single layer, and form a specific shape through the superimposition of layers (Wang et al., 2019; Li et al., 2021). In SLS 
technology, a laser is used to melt the binder and bond the ceramic powder to form (Kai et al., 2020). Compared with the DLP and SLS processes, the DIW process has the advantages of simple forming equipment, easy preparation of slurry, and high solid content of the printed green body (An et al., 2020). Recently, AM process combined with smart materials is also called $4 \mathrm{D}$ printing and piezoelectric materials are a typical type of smart materials (Kong et al., 2014; Kuang et al., 2019). Therefore, this research belongs to the category of $4 \mathrm{D}$ printing ceramics. Some researchers have tried to investigate $4 \mathrm{D}$ printing of ceramics in recent years. Liu et al. (2018) took the lead in researching ceramic $4 \mathrm{D}$ printing, where DIW was used to print a special precursor for ceramics. Firstly, the main structure was printed on a prestressed elastic substrate. When the prestress of the substrate disappears, the main structure is deformed accordingly and became a preset shape. After heating treatment, the required ceramic body was obtained. In this research, "shape change" of ceramic components is realized by using the elasticity of the composites in $4 \mathrm{D}$ printing. Grinberg et al. (2018) combined barium titanate (BTO) material with fused deposition technology, and BTO piezoelectric composites were $4 \mathrm{D}$ printed for making sensors, which can be implanted into the human body to achieve the function and effect of real-time detection of the force between prosthesis bones. However, there is a lack of exploration of the performance changes caused by the special structure of piezoelectric composites. Zeng et al. (2020) printed 1-3 BTO piezoelectric composite with honeycomb structure through $4 \mathrm{D}$ printing by combining BTO material with DLP technology. The structure can increase the acoustic performance of the piezoelectric ceramic, realize the function of ultrasonic sensing. However, due to the limitation of the piezoelectric composite structure, the voltage efficiency is only $0.1 \%$. Compared with BTO ceramics, lead zirconate titanate (PZT) ceramics also have a higher piezoelectric coefficient and are more suitable to be used as a transducer matrix material (Palmero and Bollero, 2020). Chen et al. (2017) and Yan et al. (2018) prepared PZT piezoelectric ceramics columnar array through DLP technology and assembled PZT-based ultrasonic sensors with good sensing effects. However, due to the high acoustic impedance of piezoelectric ceramics, it is not easy to match the acoustic impedance of water, which limits the underwater application of the ultrasonic transducer. At present, there are few studies on the performance and functional changes of $4 \mathrm{D}$ printed $\mathrm{PZT}$ piezoelectric composites transducer. Through editing the structure and composition of piezoelectric composites freely. 4D printing of electroactive materials including piezo-composites will present a revolutionary significance of fabricating more excellent and flexible piezoelectric materials.

This research aims to present $4 \mathrm{D}$ printing of PZT composites transducer based on the DIW process. PZT slurry with high solid content was designed and prepared and the influence of dispersant on the rheological properties of the slurry was explored. Multiple sets of piezoelectric ceramic skeletons were prepared, and the extruded rod fibers were arranged at different intervals. The electrical properties of the piezoelectric composites with different rod spacing were discussed. Finally, the output voltage evolution stimulated by the vibration of acoustic waves was presented in an underwater environment.

\section{EXPERIMENT}

\section{Process Route}

Figure 1 shows the fabricating route of underwater acoustic transducers. The PZT ceramic skeleton was printed by DIW method, and epoxy resin was filled into the skeleton to prepare piezoelectric composites. and then the piezoelectric composites were prepared into an underwater acoustic transducer.

\section{Slurry Preparation}

First, the raw PZT powder was ball milled to refine the particle size. Trisodium citrate was added as a dispersant into ethanol to prepare a premixed solution. The surfaces of the particles were quickly wetted by dispersants, which increased the energy barrier between the particles in order to eliminate the agglomeration (Walton et al., 2020). After ball milling, the mixture was filtered and dried. Finally, the PZT powder with a particle size of d50: $523 \mathrm{~nm}$ was obtained as shown in Figure 2. After powder preparation, a $10 \mathrm{wt} \%$ polyvinyl alcohol (PVA) aqueous solution containing PZT powder was prepared. The solution also contains a certain amount of ammonium polyacrylate $\left(\mathrm{PAA}-\mathrm{NH}_{4}\right)$ or sodium polyacrylate homopolymer (PAAS) as dispersant, and $1.75 \mathrm{wt} \%$ glycerin as lubricant. After stirring, the slurry was aged for $2 \mathrm{~h}$ before printing.

\section{Printing Process}

The model was sliced by the slicing software (Ultimaker Cura 4.1) to generate a Gcode file and the movement of the printer needle head is controlled by the program including layer information. The slurry was extruded from the syringe system and the power was supplied by an air pump with a pressure of $0.2 \mathrm{MPa}$. Figure 3 shows the direct ink writing $3 \mathrm{D}$ printing device and its sketch map. The height of the syringe is $115 \mathrm{~mm}$, and its moving speed is set to be $8 \mathrm{~mm} / \mathrm{s}$.

A suitable extrusion needle head is extremely important in the printing process. The smaller the needle head size is, the greater pressure is needed for extrusion. Inversely, if the size of the needle head is too large, it might result in poor printing accuracy. The height of the layer is also an important parameter of printing. If the layer height is too low, the needle head will walk in the previously extruded slurry and cause accumulation. If the height of each layer is too high, the slurry stacking will be misaligned. The diameter of the needle used in this study was $0.6 \mathrm{~mm}$ and the height of the printing layer was $0.3 \mathrm{~mm}$, so that it exists no excess drags or accumulation on each extruded fiber.

The stacking directions of the rods between the layers were perpendicular to each other and the size of the woodpile structure designed by $3 \mathrm{D}$ modeling software was set to be $20 \times 20 \times 5 \mathrm{~mm}$. Due to the viscoelasticity of the slurry, a gap could be formed between the rods in the height direction, and the shape of the model maintained. Since there were few volatile substances in the slurry, the green body shrunk insignificantly after drying. 


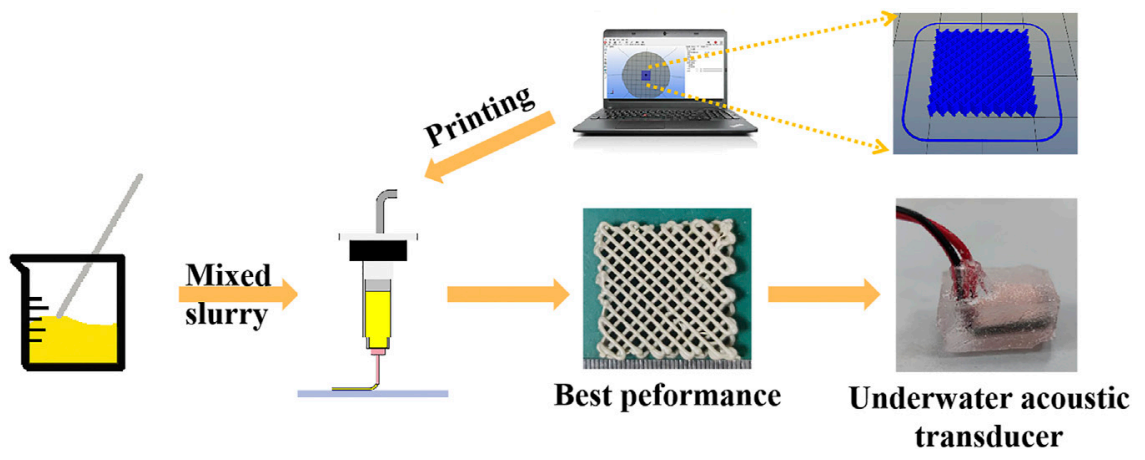

FIGURE 1 | The fabricating route of underwater acoustic transducers.

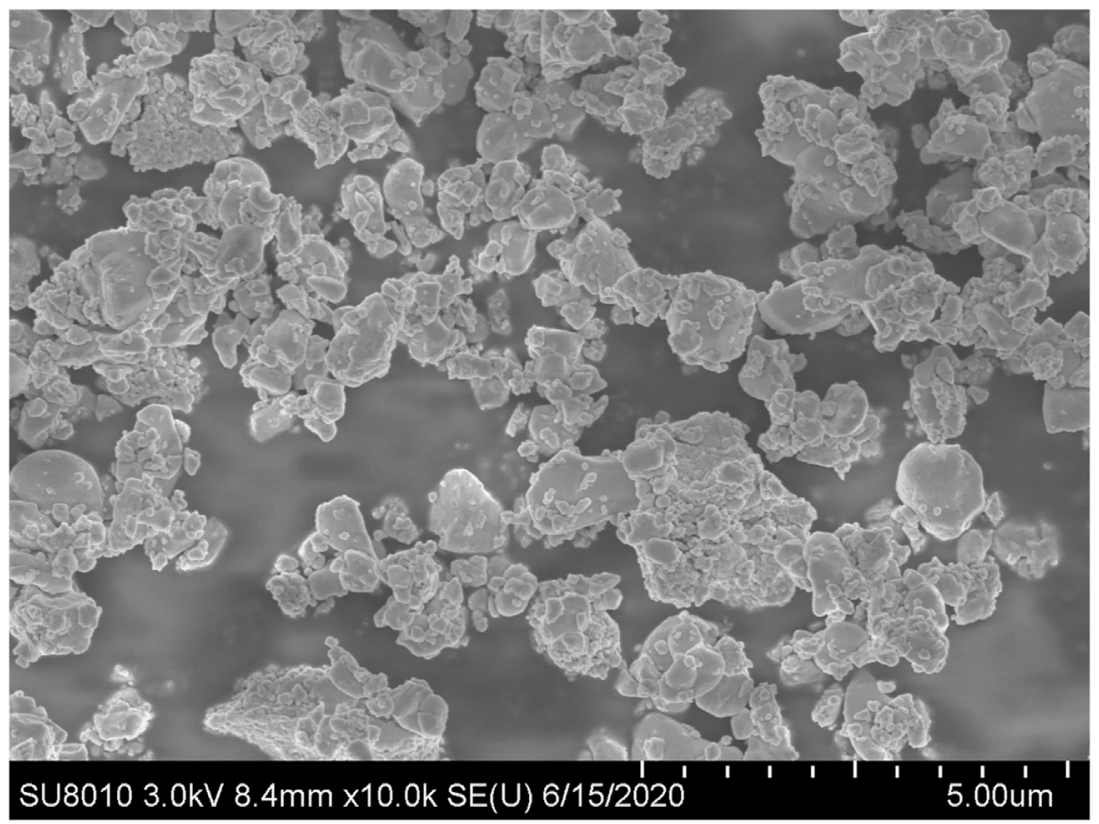

FIGURE 2 | SEM micromorphology of PZT powder.

\section{Post-Treatment Process}

The debinding and sintering of the green body were carried out separately to prevent the piezoelectric properties of PZT ceramics from being reduced due to lead volatilization. First, the green body was burned in air to fully discharge the organic phase, and then it underwent a high temperature sintering in a lead-rich environment. The debinding curve was developed by analyzing the TG-DSC curve in Figure 4.

As can be seen from the figure, the decomposition of the organic phase in the ceramic is substantially completed when the temperature reached $700^{\circ} \mathrm{C}$. The debinding process was designed to heat up to $700^{\circ} \mathrm{C}$ at a heating rate of $1^{\circ} \mathrm{C} / \mathrm{min}$, which could avoid the cracks during the debinding process. By holding the temperature at $170,250,375$, and $600^{\circ} \mathrm{C}$ for $1 \mathrm{~h}$ separately, the organic phase can fully react with oxygen and be discharged. The whole debinding process is shown in Figure 5. The sintering process was carried out in a sealed crucible, and sufficient PZT powder was used to surround the printed body, thereby providing lead-rich vapor. The sintering temperature increased from room temperature to $1250^{\circ} \mathrm{C}$ at a rate of $3^{\circ} \mathrm{C} / \mathrm{min}$, and kept it for $4 \mathrm{~h}$, so that the crystal grains could grow sufficiently. Finally, the sintered body was cooled to room temperature in the furnace.

\section{Filling and Polarization Process}

E51 epoxy resin and curing agent were mixed uniformly according to the mass ratio of $4: 1$, and the polished ceramic skeleton was immersed in the mixture. The epoxy resin can be cured within $1 \mathrm{~h}$ at $50^{\circ} \mathrm{C}$. The shrinkage during the curing process will produce mechanical stress, which will combine the epoxy resin with the ceramic skeleton. At the same time, due to the porous property of ceramic skeleton, the combination of epoxy resin and ceramic skeleton can be very stable. After the resin was 


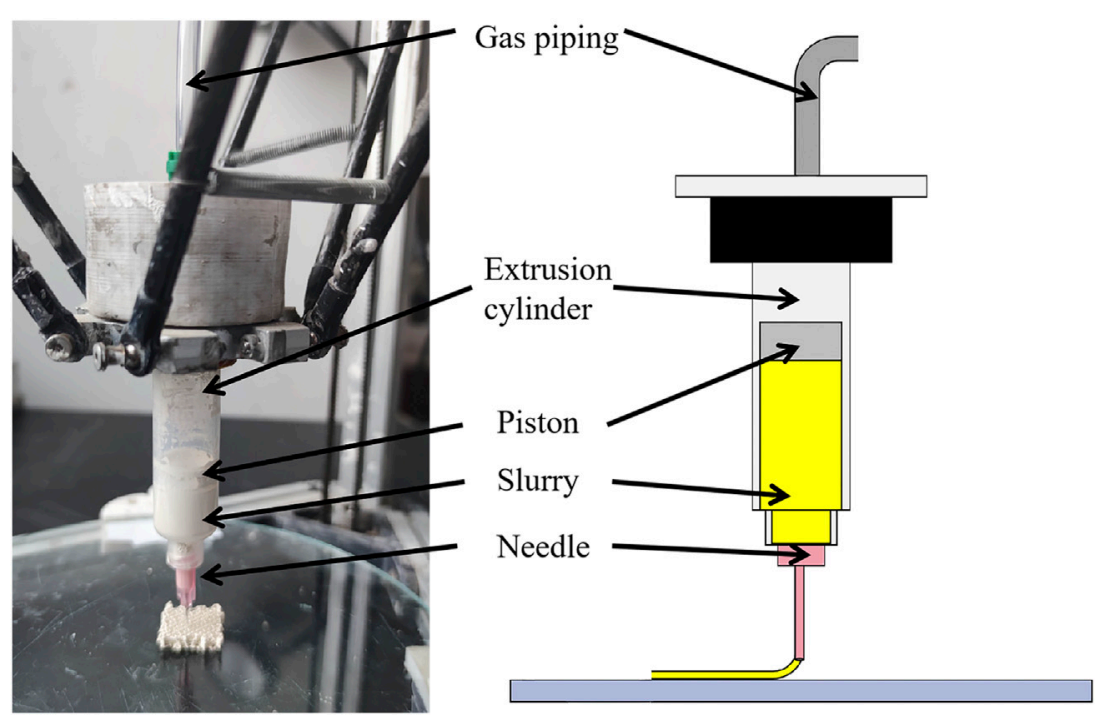

FIGURE 3 | Direct ink writing 3D printing device and sketch map.

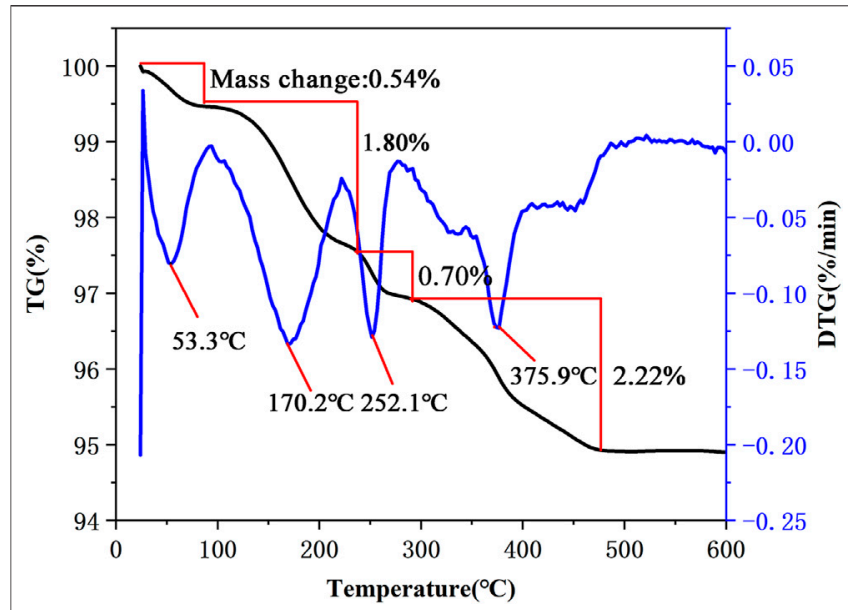

FIGURE 4 | Thermal decomposition curve of the green body in the air.

cured, the top and bottom surfaces of the piezoelectric composite were polished to make them parallel, and the ceramic part of the composites was exposed on the surface.

The top and bottom surfaces of samples were both coated with low-temperature silver slurry and then dried at $110^{\circ} \mathrm{C}$ for $30 \mathrm{~min}$ to form the silver electrode. The sample was connected to a dielectric strength tester and immersed in polymethyl silicone oil which was heated to $80^{\circ} \mathrm{C}$. Then the sample was polarized under a $2.5 \mathrm{kV} / \mathrm{mm}$ polarization field strength for $30 \mathrm{~min}$. After that, it was deposited at room temperature for $24 \mathrm{~h}$ until the discharge was completed before performance testing.

\section{Test}

A laser particle size analyzer (Mastersizer 2000) was used to measure the particle size distribution of the ball milled PZT

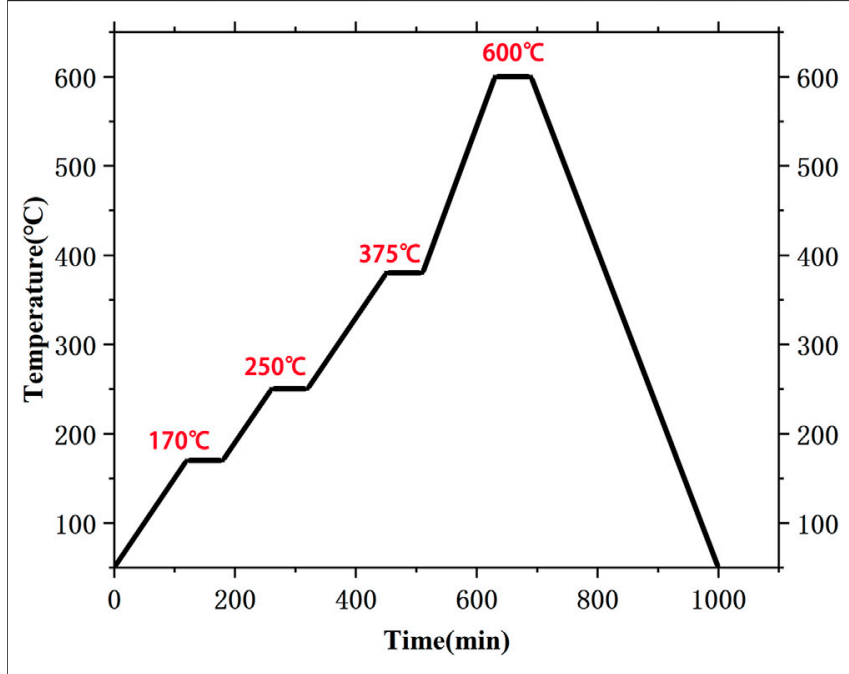

FIGURE 5 | Debinding temperature-time curve.

powder. In addition, the MCR101 dynamic shear rheometer was used to measure the rheological properties of the slurry. The German Netzsch STA449F5 thermogravimetric analyzer was used to heat the sample to $600^{\circ} \mathrm{C}$ at a heating rate of $10^{\circ} \mathrm{C} / \mathrm{min}$ to measure the weight loss of the printed body. Scanning electron microscope (SEM) was used to observe the cross section of the sintered part. The surface and cross-sectional morphology of the polished piezoelectric composites was observed by an optical microscope. The structural composition was investigated by X-ray diffractometer (Empyrean). The longitudinal piezoelectric strain coefficient $\left(d_{33}\right)$, dielectric constant $\left(\varepsilon_{r}\right)$ and dielectric loss $(\tan \delta)$ were investigated by piezometer (ZJ-3 quasistatic $d_{33}$ tester) and Novocontrol test system (Concept 80, 

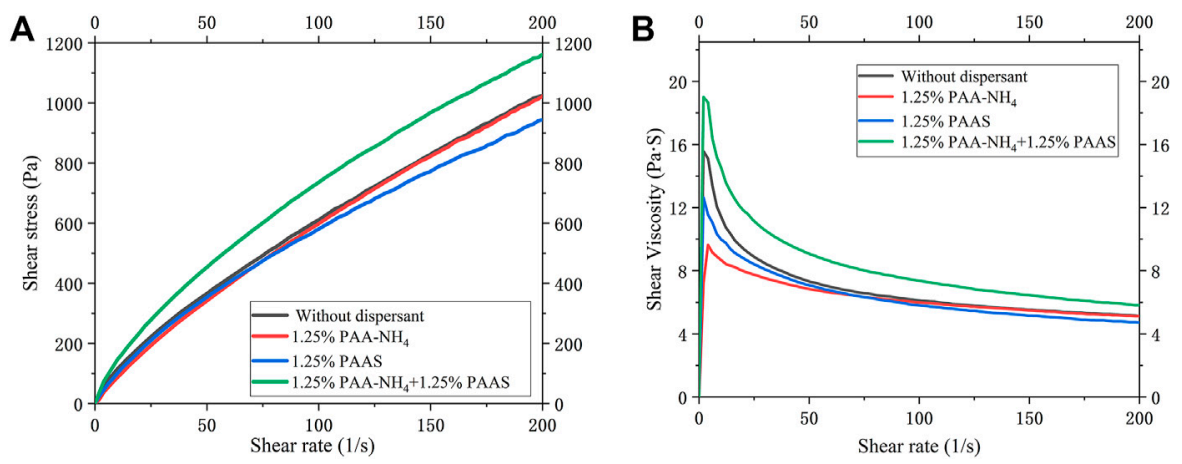

FIGURE 6 | (A) Variation curve of stress versus shear rate of PZT slurry with different dispersants; (B) Variation curve of viscosity versus shear rate of PZT slurry with different dispersants.

Germany). Three samples were made for each group of variables, and performance tests were performed on each sample three times. The average of the above test results was used as the final value.

\section{RESULTS AND DISCUSSION}

\section{Rheological Behavior of the Slurry}

The printability of the slurry is mainly determined by its rheological behavior. In DIW process, a non-Newtonian fluid slurry with viscoelasticity is usually needed. The viscous component allows the slurry to be smoothly extruded through the needle head, while the elastic component gives the extruded filament shape-retention ability and sufficient mechanical strength to support the weight of the subsequent layer (Revelo and Colorado, 2018). Using the synergistic hydrogen bonds between some macromolecules and polymer chains formed by in-situ polymerization, high-strength hydrogels with nonNewtonian fluid characteristics can be constructed in the slurry. Using PVA as a macromolecular template, PVA-PAA gel can be obtained by in-situ polymerization of acrylic acid (AA). The gel has a three-dimensional grid structure (Lewis, 2010), which can be bound with PZT powder to enhance the elastic strength of the slurry and reduce the viscosity of the slurry (Chen et al., 2017; Rac. et al., 2019; Wu et al., 2020).

PVA and acrylic additives were added to the slurry as binder and dispersant respectively, and the influence of the type and content of the dispersant on the viscosity of the slurry was investigated. First, the influence of two dispersants $\left(\mathrm{PAA}-\mathrm{NH}_{4}\right.$ and PAAS) on the viscosity of the slurry was explored. Rheological properties of PZT slurry with the same mass fraction were compared under the conditions of no dispersant, $1.25 \%$ PAA- $\mathrm{NH}_{4}, 1.25 \%$ PAAS and the mixture of two dispersants. Figure 6A shows the curve of shear stress versus shear rate, which is close to the shape and direction of the shear rate-shear stress curve of classical shear thinning fluid. It shows that the slurries with different types of dispersants all have shear thinning behavior characteristics. Compared to the viscosity levels of each slurry in Figure 6B, it can be seen that $\mathrm{PAA}-\mathrm{NH}_{4}$ reduces the viscosity of the slurry significantly better than other dispersants. When two dispersants are added at the same time, due to the large amount of PVA-PAA gel formed in the slurry, the amount of three-dimensional grid increases, which makes the viscosity of the slurry increase instead.

Furthermore, $\mathrm{PAA}-\mathrm{NH}_{4}$ was used as a dispersant to explore the most suitable addition amount. The rheological properties of the slurry in the range of $0.75 \sim 2 \%$ of the dispersant added were measured, and the results are shown in Figure 7A. It can be seen that the slurries with different add amounts of dispersant all have shear thinning behavior, and the initial viscosity is not much different.

According to the actual situation in the extrusion process, rheological data with practical significance was selected for comparison within the appropriate shear rate range. The shear rate $\gamma$ of the fluid passing through the conical needle can be calculated by the following formula (M'Barki et al., 2017; Nan et al., 2018).

$$
\gamma=\frac{4 Q}{\pi R^{3}}
$$

In the formula, $Q$ is the volume flow and $R$ is the radius of the needle. In the printing process, we used a needle with a diameter of $0.60 \mathrm{~mm}$ and a printing speed of $8 \mathrm{~mm} / \mathrm{s}$. Therefore, according to this formula, the extrusion force during the extrusion process was equivalent to a shear rate of $104.92 \mathrm{~s}^{-1}$ applied to the slurry. The rheological data of the shear viscosity flow curve when the shear rate of the gradient dispersant slurry was $105 \mathrm{~s}^{-1}$ was collected, as illustrated in Figure 7B. At this shear rate, the slurry with 2 wt\% PAA- $\mathrm{NH}_{4}$ has the highest viscosity. This is because a large amount of gel grid has generated in the slurry, and the shear force required to destroy the grid structure is also greater. The slurry added with $1.75 \mathrm{wt} \%$ of $\mathrm{PAA}-\mathrm{NH}_{4}$ has a lower viscosity, so the extrusion effect of the slurry is the best under this dispersant content.

\section{Microstructure and Phase Analysis}

The phase and microstructure of ceramics at different sintering temperatures were analyzed. The cross-sections SEM images of the samples sintered at different sintering temperatures are shown 

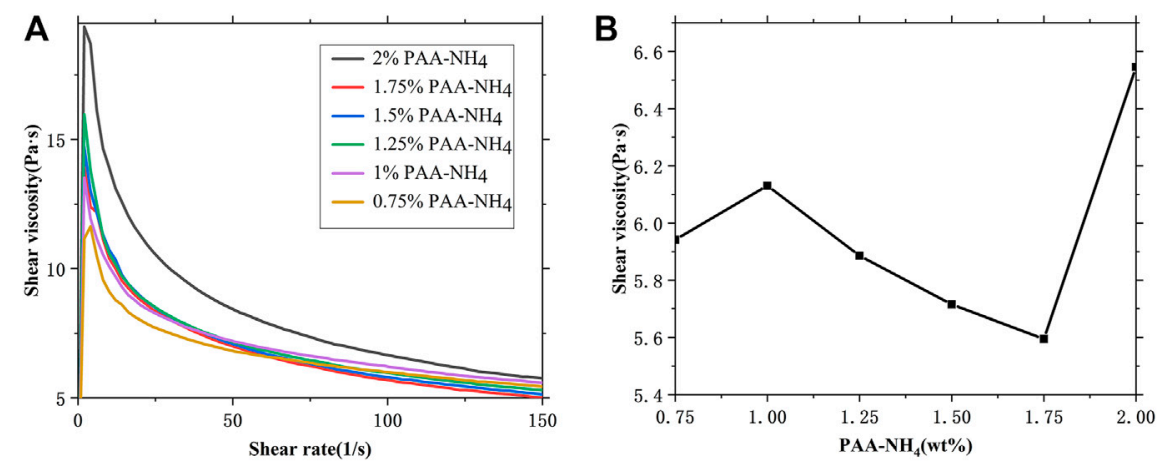

FIGURE 7 | (A) Shear rate-shear viscosity change curve of gradient dispersant content; (B) Viscosity change curve of gradient slurry concentration at $105 \mathrm{~s}^{-1}$ shear rates.

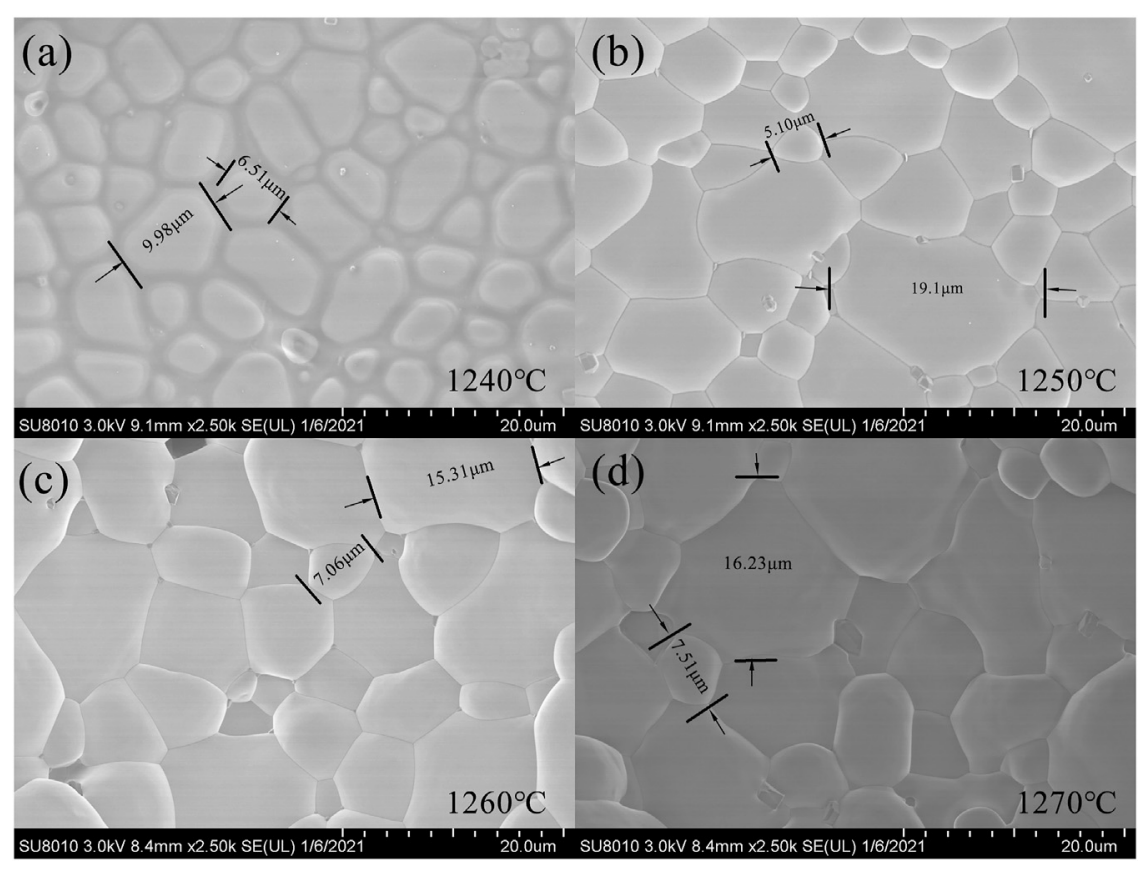

FIGURE 8 | Cross-section morphology and grain size of samples sintered at (A) $1240^{\circ} \mathrm{C}$, (B) $1250^{\circ} \mathrm{C}$, (C) $1260^{\circ} \mathrm{C}$ and (D) $1270^{\circ} \mathrm{C}$.

in Figure 8. It can be seen from the figure that when the sintering temperature is $1240^{\circ} \mathrm{C}$, the crystal grains are not fully grown. And there is a liquid phase between the grain boundaries, resulting in a small crystal grain size with a maximum size of $9.98 \mu \mathrm{m}$. When the temperature is raised to $1250^{\circ} \mathrm{C}$, the grain size increases (the maximum size is $19.1 \mu \mathrm{m}$ ), and the grain boundaries are clear. The actual density of the sintered sample is $7.63 \mathrm{~g} / \mathrm{cm}^{3}$ and the relative density is $97.8 \%$. As the temperature further increased, the small crystal grains grew further, but when the temperature raised to $1270^{\circ} \mathrm{C}$, the grain boundaries were remelted due to the high temperature, resulting in unclear grain boundaries.

It can be seen from Figure 9 that when the sintering temperature is $1240^{\circ} \mathrm{C}$ and the heat preservation time is $4 \mathrm{~h}$, the phase structure of ceramics has split peaks in the range of $2 \theta=21 \sim 22.5^{\circ}$ and $43 \sim 45^{\circ}$, which shows that the ceramic is in the quasi-homotype phase boundary area where the tripartite phase and the tetragonal phase coexist. And the phase diagram has a split peak at $2 \theta=32^{\circ}$, indicating that the ceramic has a pyrochlore phase structure when the firing temperature is low, and a tripartite perovskite structure can't be formed. However, as the temperature increased to $1250 \sim 1270 \mathrm{C}$, the pyrochlore phase structure in the sintered body is eliminated, and the pure tripartite perovskite structure is formed. From the results of grain growth and phase analysis, $1250 \sim 1260^{\circ} \mathrm{C}$ is the best sintering temperature range.

\section{Performance}

The influence of structural parameters on the properties of piezoelectric composites was discussed by changing rod spacing 


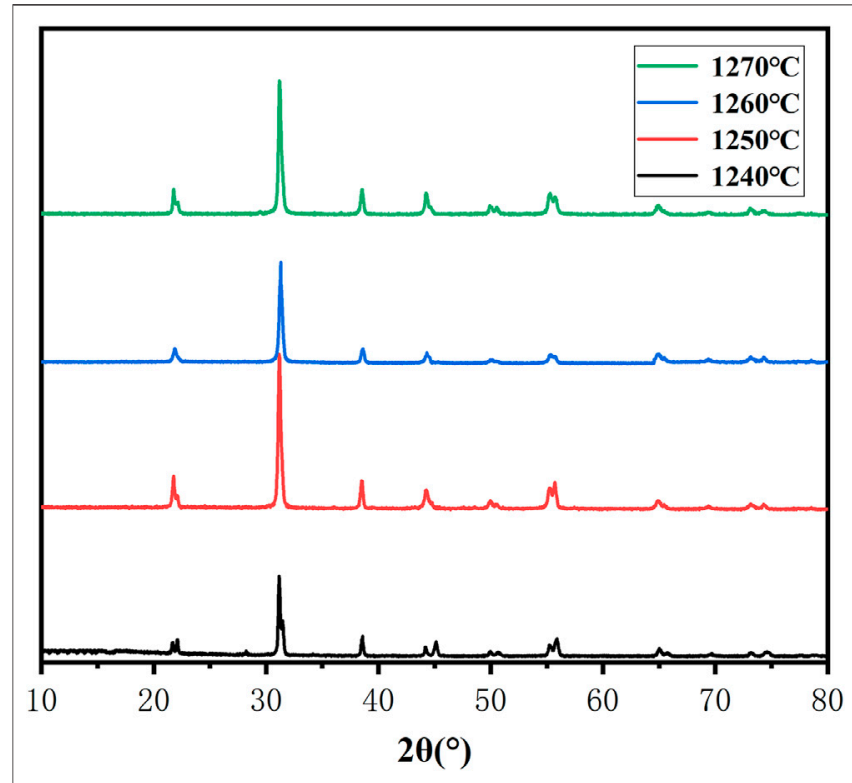

FIGURE 9|X-ray diffraction pattern of ceramics sintered at 1240, 1250, 1260 and $1270^{\circ} \mathrm{C}$.

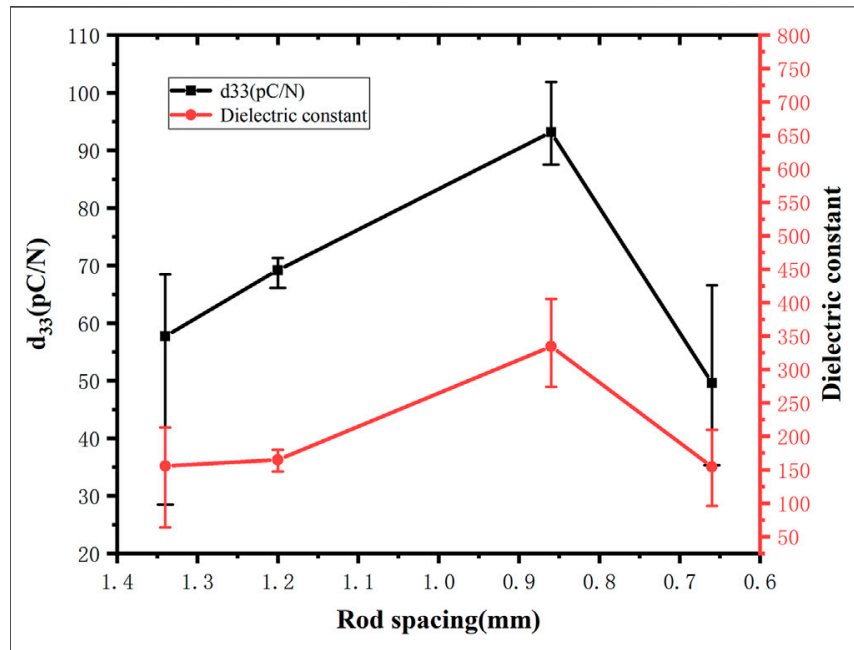

FIGURE 11 | The change curve of $d_{33}$ and relative permittivity of piezoelectric composites with diffrente rod spacings.
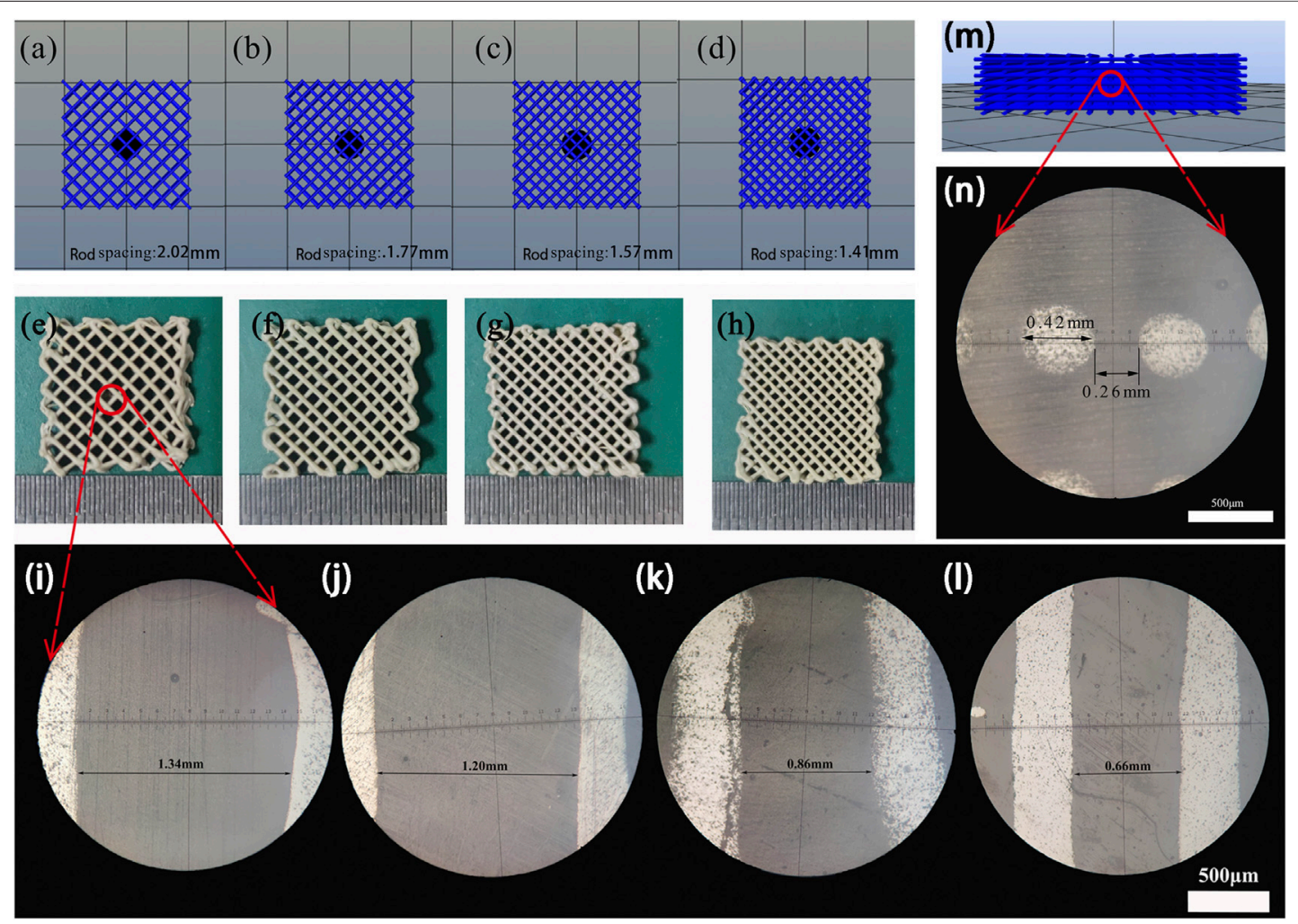

FIGURE 10 ( $\mathbf{A}, \mathbf{E}$, I) 20\% filling density model, sintered body and size micrograph; (B, F, J) 23\% filling density model, sintered body and size micrograph; (C, G, K) 26\% filling density model, sintered body and size micrograph; (D, H, L) 29\% filling density model, sintered body and size micrograph; (M, N) Model cross section and size micrograph. 
of the ceramic skeleton. The filling density was respectively set to $20,23,26$, and $29 \%$, and the printing effect of the piezoelectric ceramic skeleton is shown in Figures 10A-H. After filling the resin, an optical microscope was used to measure the distance between the piezoelectric composite rods, and the corresponding rod spacing was $1.34,1.20,0.86,0.66 \mathrm{~mm}$, as shown in Figures 10I-L. Since the overall structure shrinks uniformly after sintering, the size in Figure $\mathbf{1 0 N}$ can be used to calculate the rod diameter and layer height shrinkage. Through calculation, the diameter shrinkage rate of the rod is $30 \%$. After the prepared 3-3 piezoelectric composite was polished and polarized, its piezoelectric constant $\left(d_{33}\right)$ and relative dielectric constant $(\varepsilon r)$ were tested. These performance test data were used to characterize the influence of the distance between the rods on the performance of the piezoelectric composites.

The $d_{33}$ and relative permittivity of the 3-3 piezoelectric composites were tested as a function of the distance between the rods. As shown in Figure 11, the error bars in the figure indicate the maximum and minimum values of the piezoelectric coefficient and the relative permittivity of the sample. Within the range of $0.66 \sim 1.34 \mathrm{~mm}$ rod spacing, both $d_{33}$ and $\varepsilon r$ increase first and then decrease. When the rod spacing is $0.86 \mathrm{~mm}$, the electrical performance reaches the maximum, the maximum $d_{33}$ is $103 \mathrm{pC} / \mathrm{N}$, and $\varepsilon r$ is 274.34 , and the smaller the dielectric constant is, and the smaller the dielectric constant of the piezoelectric composites, the smaller the dielectric loss. This is because as the distance between the rods increases, the content of the ceramic phase decreases accordingly. When the composites are under stress, the greater the force acting on the piezoelectric ceramic frame, the more surface induced charges are generated (Runt et al., 1985; Liu et al., 2017; Jin et al., 2020; Wu et al., 2020). However, with the further decrease of the rod spacing, the piezoelectric and dielectric decrease. This is because as the distance between the rod decreases, there is overlap in the vertical direction during the printing process, which converts the precise 3-3 type into piezoelectric composites with other structures (Liu et al., 2017). This leads to the formation of internal closed cells inside the ceramic part after sintering and increases the number of defects. This phenomenon means that the internal pores of the ceramic parts can't be filled and the polarization process is affected, resulting in an increase in $\tan \delta$ (Runt et al., 1985).

Through this investigation, it is found that the reduction of the rod spacing has the law of first increasing and then decreasing in the electrical properties of the $4 \mathrm{D}$ printed 3-3 piezoelectric composites. Therefore, with the help of $4 \mathrm{D}$ printing technology, we can freely design and change the structural parameters, and explore the influence rules of the parameters, so as to regulate the performance of the structure to meet the controllable changes in performance and functions.

\section{Underwater Acoustic Transducer}

The underwater acoustic transducer uses piezoelectric composites with copper foil adhered to the surface as the piezoelectric element. At the same time, Polyurethane (PU) is used as the matching layer of the transducer because of its acoustic impedance close to that of water (Sasikumar et al., 2014; Bian et al., 2020; Yf et al., 2021). In order to characterize the sound-to-electric conversion function of the manufactured underwater acoustic transducer, a test scene as shown in Figure 12 was constructed to verify. A signal generator was used to generate electrical signals with different waveforms and frequencies. The signals were then inputted into the speaker to make it emit sound signals of the same waveform and frequency. The distance between the speaker and the sensor is $450 \mathrm{~mm}$, and the sound wave signal generated by the speaker was converted into an electric signal by the underwater acoustic transducer, and the electric signal was displayed on a digital oscilloscope.

Under the input voltage $\left(V_{i}\right)$ of $2 \sim 24 \mathrm{~V}$, the loudspeaker can emit $100 \mathrm{kHz}$ and with different amplitudes acoustic signals. After receiving the acoustic signal, the underwater acoustic transducer converts it into a response voltage $\left(V_{P P}\right)$, as shown in Figure 13A $V_{P P}$ is positively related to $V_{i}$. When the input voltage was $24 \mathrm{~V}$, the output voltage was $162 \mathrm{mV}$, and the voltage conversion efficiency was $0.675 \%$. The demonstration results show that the acoustic electrical conversion of piezoelectric materials in water can be realized by $4 \mathrm{D}$ printing. Through changing the structural parameters of piezoelectric composites, the conversion efficiency of the transducer also changes accordingly. Under the optimal printing parameters, the prepared underwater acoustic transducer can generate a maximum voltage of $162 \mathrm{mV}$. At the same time, through the change of the waveform displayed on the oscilloscope, people can detect the change of the underwater sound source, so as to get a warning.

Above all, this $4 \mathrm{D}$ printing method can quickly and autonomously control the printing structure and realize the detection of controllable changes, which is an advantage that traditional manufacturing methods do not have. And in the future, it can be used to prepare optimized piezoelectric structures to further improve the performance of underwater acoustic transducers, which is expected to lead the development direction of $4 \mathrm{D}$ printing functional devices.

\section{CONCLUSIONS}

This article presents the application of $4 \mathrm{D}$ printing in underwater acoustic transducers. The combination of piezoelectric material PZT and direct ink writing is conducive to the development of underwater detection intelligent equipment with high performance and multi-function. The specific conclusions are as follows,

1. The PZT piezoelectric ceramic skeleton was prepared by direct ink writing. The influence of the dispersant on the viscosity of the slurry was explored. It was found that when the addition amount of the dispersant ammonium polyacrylate in the slurry is $1.75 \mathrm{wt} \%$, the slurry has the best printing effect. In addition, the green body has the best sintering effect at $1250 \sim 1260^{\circ} \mathrm{C}$, which can form a pure trigonal perovskite structure, the relative density after sintering reaches $97.8 \%$.

2. The performance of piezoelectric composites with different rod spacing was tested. As the distance between the rods decreases, the $d_{33}$ and $\varepsilon_{r}$ of the piezoelectric composite first increase and then decrease. When the filling density was $26 \%$, the printed structure had the best electrical performance $\left(d_{33}=103 \mathrm{pC} / \mathrm{N}\right.$ and $\left.\varepsilon_{r}=274.34\right)$. 


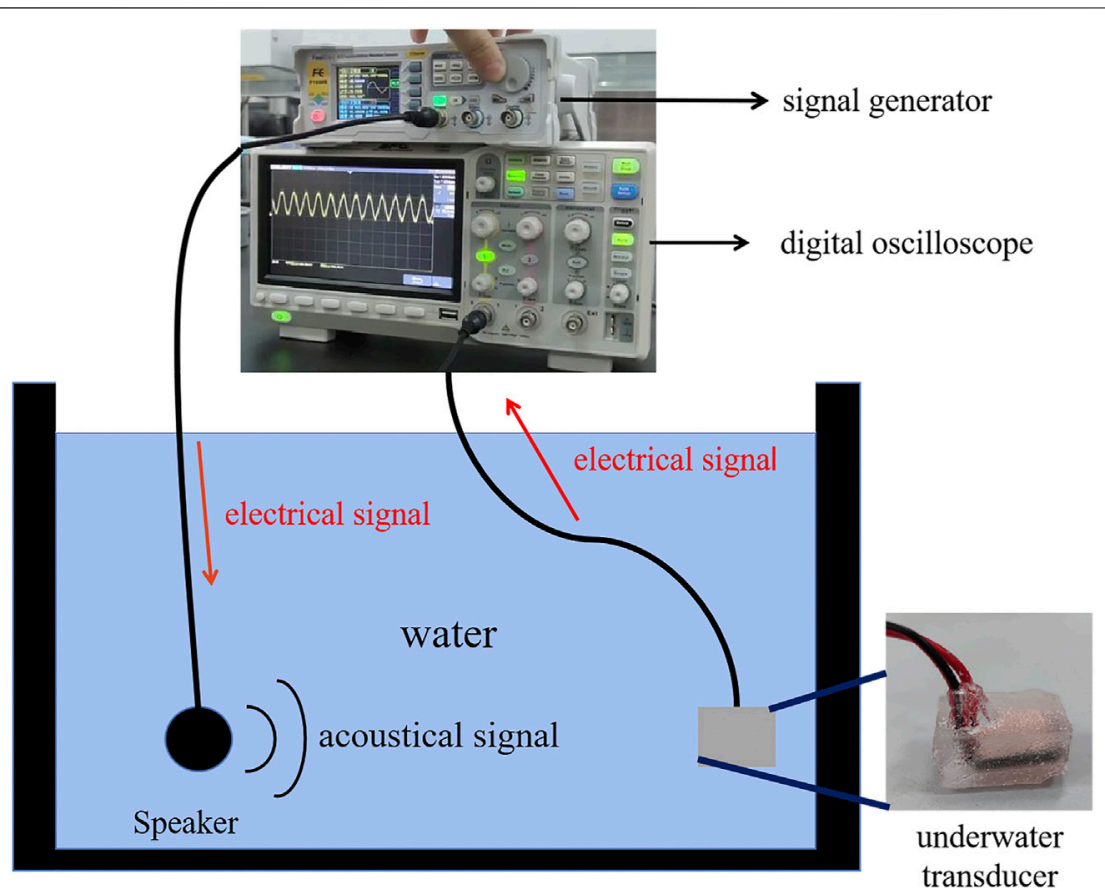

FIGURE 12 | Signal receiving test of underwater acoustic transducer.

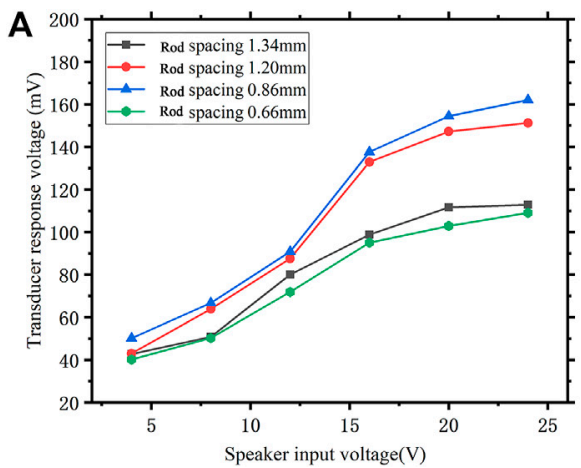

FIGURE 13 | (A) Comparison of signal generator input and digital oscilloscope output; at $100 \mathrm{kHz}$ varies with the output voltage of the signal generator.

3. A $4 \mathrm{D}$ printed sample was used to prepare an underwater acoustic transducer. Piezoelectric composites with the best electrical performance also have the highest voltage output, and the output voltage maximum was $162 \mathrm{mV}$. This verifies that this $4 \mathrm{D}$ printing method can quickly achieve structural changes, thereby obtaining the best performance.

Therefore, it is necessary to further explore the advantages of using $4 \mathrm{D}$ printing technology to realize the free design of piezoelectric structures, and manufacturing of piezoelectric composites. These piezoelectric devices have independently adjustable piezoelectric characteristics and functions, which

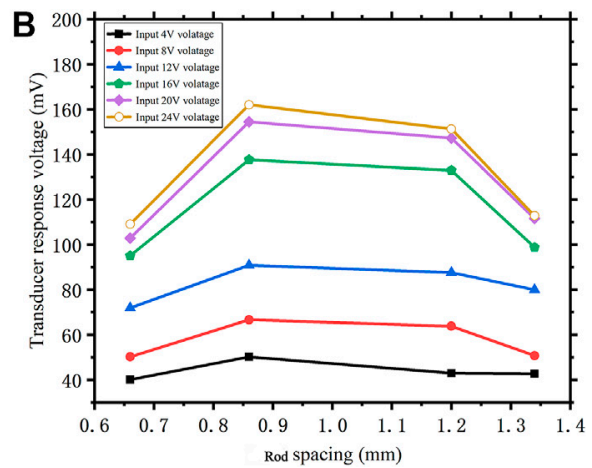

(B) The peak-to-peak $V_{p p}$ response of the underwater acoustic transducer have great potential for underwater detection and communication applications.

\section{DATA AVAILABILITY STATEMENT}

The original contributions presented in the study are included in the article/Supplementary Material, further inquiries can be directed to the corresponding author.

\section{AUTHOR CONTRIBUTIONS}

Experiments were designed by KL. QZ completed the main experimental part. CZ and CS, designed the slurry formula; CY 
and $\mathrm{JH}$, performed performance tests on experimental samples; SZ, $\mathrm{YZ}$, and $\mathrm{YF}$ designed and assembled a $3 \mathrm{D}$ printer. The main paper was written by QZ and KL revised the paper. All authors discussed the results and their implications, participated in the revised manuscripts at various stages, and approved for publication.

\section{FUNDING}

This work was supported by the National Innovation and Entrepreneurship Training Program for College Students

\section{REFERENCES}

An, T., Hwang, K. T., Kim, J. H., and Kim, J. (2020). Extrusion-based 3D Direct Ink Writing of NiZn-Ferrite Structures with Viscoelastic Ceramic Suspension[J]. Ceramics Int., 46(5):6469-6476. doi:10.1016/j.ceramint.2019.11.127

Bian, J., Wang, Y., Liu, Z., Shen, M., Zhao, H., Sun, Y., et al. (2020). Ultra-wideband Underwater Acoustic Transducer with a Gradient Impedance Matching Layer [J]. Appl. Acoust. 175. doi:10.1016/j.apacoust.2020.107789

Bowen, C. R., and Topolov, V. Y. (2003). Piezoelectric Sensitivity of PbTiO3-Based Ceramic/polymer Composites with 0-3 and 3-3 Connectivity. Acta Materialia 51 (17), 4965-4976. doi:10.1016/S1359-6454(03)00283-0

Chen, K., Liu, J., Yang, X., and Zhang, D. (2017). Preparation, Optimization and Property of PVA-HA/PAA Composite Hydrogel. Mater. Sci. Eng. C 78 (sep), 520-529. doi:10.1016/j.msec.2017.04.117

Coppola, B., Tardivat, C., Richaud, S., Tulliani, J.-M., Montanaro, L., and Palmero, P. (2021). 3D Printing of Dense and Porous Alkali-Activated Refractory Wastes via Direct Ink Writing (DIW). J. Eur. Ceram. Soc. 41, 3798-3808. doi:10.1016/j. jeurceramsoc.2021.01.019

Grinberg, D., Siddique, S., Le, M. Q., Liang, R., Capsal, J. F., and Cottinet, P. J. (2018). 4D Printing Based Piezoelectric Composite for Medical Applications. J. Polym. Sci. Part. B: Polym. Phys. 57 (3), 109-115. doi:10.1002/polb.24763

Jin, C., Hao, N., Xu, Z., Trase, I., Nie, Y., Dong, L., et al. (2020). Flexible Piezoelectric Nanogenerators Using Metal-Doped ZnO-PVDF Films. Sensors Actuators A: Phys. 305, 111912. doi:10.1016/j.sna.2020.111912

Kai, L., Jiang, W., Tian, W., and Huajun, S. (2020). Effects of Carbon Content on Microstructure and Mechanical Properties of SiC Ceramics Fabricated by SLS/ RMI Composite Process - ScienceDirect[J]. Ceramics Int. 46 (14), 22015-22023. doi:10.1016/j.ceramint.2020.05.18

Kong, Y. L., Tamargo, I. A., Kim, H., and Kim, J. (2014). 4D Printing: MultiMaterial Shape Change[J]. Architectural Des. 84 (1), 116-121. doi:10.1002/ad. 1710

Kuang, X., Roach, D. J., Wu, J., Hamel, C. M., Ding, Z., Wang, T., et al. (2019). Advances in 4D Printing: Materials and Applications[J]. Adv. Funct. Mater. 29 (2), 1805290.1-1805290.23. doi:10.1002/adfm.201805290

Lewis, J. A. (2010). Colloidal Processing of Ceramics. J. Am. Ceram. Soc. 83 (10), 2341-2359. doi:10.1111/j.1151-2916.2000.tb01560.x

Li, D., Wu, M., Oyang, P., and Xu, X. (2006). Cymbal Piezoelectric Composite Underwater Acoustic Transducer. Ultrasonics 44 (8), e685-e687. doi:10.1016/j. ultras.2006.05.127

Li, Y., Mao, Q., Yin, J., Wang, Y., Fu, J., and Huang, Y. (2021). Theoretical Prediction and Experimental Validation of the Digital Light Processing (DLP) Working Curve for Photocurable Materials. Additive Manufacturing 37, 101716. doi:10.1016/j.addma.2020.101716

Liu, G., Zhao, Y., Wu, G., and Lu, J. (2018). Origami and 4D Printing of ElastomerDerived Ceramic Structures[J]. Sci. Adv. 4 (8), eaat0641. doi:10.1126/sciadv. aat0641

Liu, J., Kim, A. Y., Wang, L. Q., Palmer, B. J., Chen, Y. L., Bruinsma, P., et al. (1996). Self-assembly in the Synthesis of Ceramic Materials and Composites. Adv. Colloid Interf. Sci., 69, 131-180. doi:10.1016/S0001-8686(96)00309-0

Liu, W., Lv, L., Li, Y., Wang, Y., Wang, J., Xue, C., et al. (2017). Effects of Slurry Composition on the Properties of 3-1 Type Porous PZT Ceramics Prepared by
(202010497012), self-determined and innovative research funds of WUT (2020-CL-B1-05), the National Natural Science Foundation of China (Grant Nos. U1806221, 51672198), Innovation and Development Project of Zibo City (2017CX01A022), Instruction \& Development Project for National Funding Innovation Demonstration Zone of Shandong Province (2017-41-1, 2017-41-3, 2018ZCQZB01, 2019ZCQZB03), Central Guiding Local Science and Technology Development Special Funds (Grant Nos. 2060503), and Key Research \& Design Program of Shandong Province (2019GGX102011).
Ionotropic Gelation - ScienceDirect[J]. Ceramics Int. 43 (8), 6542-6547. doi:10. 1016/j.ceramint.2017.02.079

M'Barki, A., Bocquet, L., and Stevenson, A. (2017). Linking Rheology and Printability for Dense and Strong Ceramics by Direct Ink Writing[J]. Scientific Rep. 7 (1), 6017. doi:10.1038/s41598-017-06115-0

Meng, X., Xu, J., Zhu, J., et al. (2020). Porous yttria-stabilized zirconia ceramics with low thermal conductivity via a novel foam-gelcasting method. J. Mater. Sci. 55. doi:10.1007/s10853-020-04900-3

Nan, B., Olhero, S., Pinho, R., Vilarinho, P. M., Button, T. W., and Ferreira, J. M. F. (2018). Direct Ink Writing of Macroporous lead-free Piezoelectric Ba $0.85 \mathrm{Ca}$ $0.15 \mathrm{Zr} 0.1 \mathrm{Ti} 0.9$ O 3. J. Am. Ceram. Soc. 102 (7633), 3191-3203. doi:10.1111/ jace. 16220

Newnham, R. E., Skinner, D. P., and Cross, L. E. (1978). Connectivity and Piezoelectric-Pyroelectric Composites. Mater. Res. Bull. 13 (5), 525-536. doi:10.1016/0025-5408(78)90161-7

Palmero, E. M., and Bollero, A. (2020). 3D and 4D Printing of Functional and Smart Composite Materials[J]. Reference Module in Materials Ence and Materials Engineering. doi:10.1016/b978-0-12-819724-0.00008-2

Rac, V., Lević, S., Balanč, B., Olalde Graells, B., and Bijelić, G. (2019). PVA Cryogel as Model Hydrogel for Iontophoretic Transdermal Drug Delivery Investigations. Comparison with PAA/PVA and PAA/PVP Interpenetrating Networks. Colloids Surf. B Biointerfaces 180, 441-448. doi:10.1016/j.colsurfb. 2019.05.017

Revelo, C. F., and Colorado, H. A. (2018). 3D Printing of Kaolinite clay Ceramics Using the Direct Ink Writing (DIW) Technique. Ceramics Int. 44, 5673-5682. doi:10.1016/j.ceramint.2017.12.219

Rouffaud, R., Granger, C., Hladky-Hennion, A.-C., Thi, M.P., and Levassort, F. (2015). Tonpilz Underwater Acoustic Transducer Integrating Lead-free Piezoelectric Material. Phys. Proced. 70, 997-1001. doi:10.1016/j.phpro.2015. 08.208

Runt, J., Safari, A., Galgoci, E. C., and Newnham, R. E. (1985). The Influence of Interfacial Adhesion on the Piezoelectric Response of Electroceramic/polymer Composites. Ferroelectrics Lett. Section 5, 15-20. doi:10.1080/ 07315178508202461

Sasikumar, K., Manoj, N. R., Mukundan, T., and Khastgir, D. (2014). Design of XNBR Nanocomposites for Underwater Acoustic Sensor Applications: Effect of MWNT on Dynamic Mechanical Properties and Morphology. J. Appl. Polym. Sci., 131(8):a-n. doi:10.1002/app.40752

Tian, F., Liu, Y., Ma, R., Li, F., Xu, Z., and Yang, Y. (2021). Properties of PMN-PT Single crystal Piezoelectric Material and its Application in Underwater Acoustic Transducer. Appl. Acoust. 175 (4), 107827. doi:10.1016/j.apacoust.2020.107827

Tressler, J. F., Alkoy, S., Dogan, A., and Newnham, R. E. (1999). Functional Composites for Sensors, Actuators and Transducers. Composites A: Appl. Sci. Manufacturing 30 (4), 477-482. doi:10.1016/S1359-835X(98)00137-7

Viganò, F., Cristiani, C., and Annoni, M. (2017). Ceramic Sponge Abrasive Waterjet (AWJ) Precision Cutting through a Temporary Filling Procedure. J. Manufacturing Process. 28 (1), 41-49. doi:10.1016/j. jmapro.2017.05.014

Walton, R. L., Fanton, M. A., Meyer, R. J., and Messing, G. L. (2020). Dispersion and Rheology for Direct Writing lead-based Piezoelectric Ceramic Pastes with Anisotropic Template Particles. J. Am. Ceram. Soc. 103, 6157-6168. doi:10. $1111 /$ jace. 17350 
Wang, L., Luo, Y., Yang, Z., Dai, W., Liu, X., Yang, J., et al. (2019). Accelerated Refilling Speed in Rapid Stereolithography Based on Nano-Textured Functional Release Film. Additive Manufacturing 29, 100791. doi:10.1016/j.addma.2019. 100791

Woodward, D. I., Purssell, C. P., Billson, D. R., Hutchins, D. A., and Leigh, S. J. (2015). Additively-manufactured Piezoelectric Devices. Phys. Status Solidi A. 212 (10), 2107-2113. doi:10.1002/pssa.201532272

Wu, L., Li, L., Fan, L., Tang, P., Yang, S., Pan, L., et al. (2020). Strong and Tough PVA/PAA Hydrogel Fiber with Highly Strain Sensitivity Enabled by Coating MWCNTs - ScienceDirect[J]. Composites Part A: Appl. Sci. Manufacturing 138. doi:10.1016/j.compositesa.2020.106050

Wu, W., Yin, X., Dai, B., Kou, J., Ni, Y., and Lu, C. (2020). Water Flow Drived PiezoPhotocatalytic Flexible Films: Bi-piezoelectric Integration of $\mathrm{ZnO}$ Nanorods and PVDF. Appl. Surf. Sci. 517, 146119. doi:10.1016/j.apsusc.2020.146119

Yan, C., Xiulan, B., Chi-Man, W., Cheng, J., Wu, H., Song, H., et al. (2018). PZT Ceramics Fabricated Based on Stereolithography for an Ultrasound Transducer Array Application[J]. Ceramics Int. 44, 22725-22730. doi:10.1016/j.ceramint.2018.09.055
Yf, A., Iik, A., Guan, H., and Peng, Z. (2021). A Review on Polymer-Based Materials for Underwater Sound Absorption[J]. Polym. Test. doi:10.1016/j.polymertesting.2021.107115

Zeng, Y., Jiang, L., Sun, Y., Yang, Y., Quan, Y., Wei, S., et al. (2020). 3D-Printing Piezoelectric Composite with Honeycomb Structure for Ultrasonic Devices. Micromachines 11 (8), 713. doi:10.3390/mi11080713

Conflict of Interest: The authors declare that the research was conducted in the absence of any commercial or financial relationships that could be construed as a potential conflict of interest.

Copyright (C) 2021 Liu, Zhang, Zhou, Shi, Sun, Sun, Yin, Hu, Zhou, Zhang and Fu. This is an open-access article distributed under the terms of the Creative Commons Attribution License (CC BY). The use, distribution or reproduction in other forums is permitted, provided the original author(s) and the copyright owner(s) are credited and that the original publication in this journal is cited, in accordance with accepted academic practice. No use, distribution or reproduction is permitted which does not comply with these terms. 